Original article

\title{
Co-occurrence of aggressive behavior and depressive symptoms in early adolescence: A longitudinal multi-informant study ${ }^{i / 2}$
}

\section{Comorbidité des conduites d'agression et des symptômes dépressifs au cours de la prime adolescence: une étude longitudinale à procédure multi-informateurs}

\author{
D. Van der Giessen ${ }^{\mathrm{a}, *}$, S. Branje ${ }^{\mathrm{a}}$, G. Overbeek ${ }^{\mathrm{a}}$, T. Frijns ${ }^{\mathrm{b}}$, P.A.C. van Lier ${ }^{\mathrm{c}}$, H.M. Koot ${ }^{\mathrm{c}}$, W. Meeus $^{\mathrm{a}, \mathrm{d}}$ \\ a Utrecht University, P.O. Box 80140, 3508 TC Utrecht, The Netherlands \\ ${ }^{\mathrm{b}}$ Trimbos Institute, P.O. Box 725, 3500 AS Utrecht, The Netherlands \\ c VU University Amsterdam, Van der Boechorststraat 1, 1081 BT Amsterdam, The Netherlands \\ d Tilburg University, P.O. Box 90153, 5000 LE Tilburg, The Netherlands
}

\section{A R T I C L E I N F O}

\section{Article history:}

Received 20 September 2011

Received in revised form 6 March 2013

Accepted 12 March 2013

\begin{abstract}
A B S T R A C T
Introduction. - Aggressive behavior and depressive symptoms co-occur frequently during adolescence. The failure model argues that the onset of aggressive behavior is more likely to precede the onset of depressive symptoms, whereas the acting-out model states that depressed mood predicts subsequent aggressive behavior. However, few longitudinal studies have examined with fully recursive models the temporal ordering of aggressive behavior and depressive symptoms during early adolescence.

Objective. - Therefore, this study examined the bidirectional associations between aggressive behavior and depressive symptoms during early adolescence, using a multi-informant cross-lagged panel model. Gender differences were also investigated.

Method. - We used data from three waves of questionnaire data that were annually collected among 497 early adolescents (56.9\% boys) and their parents, thereby covering an age range from 12 to 15 . Adolescents reported on their depressive symptoms and the parents reported on the adolescents' aggressive behavior. Results. - Cross-lagged path analyses showed that early adolescents' aggressive behavior predicted subsequent depressive symptoms, but early adolescents' depressive symptoms did not predict aggressive behavior. Findings were similar for boys and girls.

Conclusion. - Thus, our results provide support for the failure model and suggest that reducing aggressive behavior at the start of adolescence might reduce the risk for subsequent depressive symptoms.
\end{abstract}

(c) 2013 Elsevier Masson SAS. All rights reserved.

\section{R É S U M É}

Introduction. - Les conduites agressives et les symptômes dépressifs apparaissent souvent simultanément à l'adolescence. Le modèle " échec " soutient que l'apparition des conduites agressives précède l'apparition de symptômes dépressifs, tandis que le modèle " acting-out » stipule que les symptômes dépressifs prédisent les conduites agressives subséquentes. Peu d'études longitudinales ont toutefois examiné la séquence temporelle de ces phénomènes à l'adolescence, en utilisant des modèles récursifs acheminatoires. objectif. - Cette étude examine les relations bidirectionnelles entre les conduites agressives et les symptômes dépressifs à l'adolescence, à l'aide de données longitudinales provenant de diverses sources d'informations. Des différences de genre sont également vérifiées.

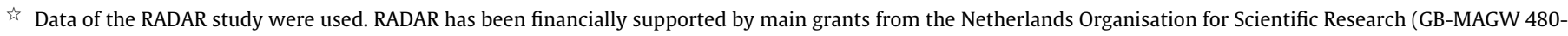

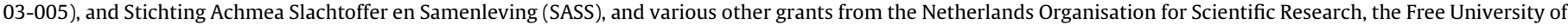
Amsterdam and Utrecht University.

* Corresponding author.

E-mail addresses: D.vandergiessen@uu.nl(D.Van der Giessen),S.branje@uu.nl(S.Branje), G.overbeek@uu.nl(G.Overbeek),T.frijns@uu.nl(T.Frijns),PAC.van.Lier@psy.vu.nl (P.A.C. van Lier), JM.Koot@psy.vu.nl (H.M. Koot), W.meeus@uu.nl (W. Meeus).
} 
Méthode. - Les données proviennent de questionnaires, colligées sur trois années consécutives, de 497 adolescents $(56,9 \%$ garçons ; âgés de 12 à 15 ans) et de leurs parents. Les symptômes dépressifs étaient évalués par l'adolescent lui-même, alors que les conduites agressives étaient évaluées par les parents. Résultats. - Des analyses acheminatoires ont montré que les conduites agressives des adolescents prédisent significativement les symptômes dépressifs ultérieurs. La relation inverse n'est toutefois pas significative. Les modèles ne semblent pas différer selon le sexe.

Discussion. - Ces résultats apportent du soutien au modèle "échec». Le fait de réduire les comportements agressifs au début de l'adolescence pourrait aider à réduire le risque de symptômes dépressifs subséquents.

@ 2013 Elsevier Masson SAS. Tous droits réservés.

Adolescents showing symptoms of depression or aggression are at increased risk for later maladjustment (Colman et al., 2009; Fergusson \& Woodward, 2002). Moreover, adolescents with depressive symptoms often report dysfunctions in the regulation of aggressive expressions (Jackson, Kuppens, Sheeber, \& Allen, 2011; Kashani, Dahlmeier, Borduin, Soltys, \& Reid, 1995). Aggressive behavior and depressive symptoms also co-occur frequently during adolescence, with co-occurrence rates ranging from 8.5 to $83.3 \%$ (Angold, Costello, \& Erkanli, 1999). Co-occurrence is related to greater impairment in daily functioning, poorer overall adjustment, and more frequent later psychiatric disorders than single symptom occurrence (Keiley, Lofthouse, Bates, Dodge, \& Pettit, 2003). Moreover, during early adolescence important changes occur in aggressive behavior and depressive symptoms (e.g., Bongers, Koot, van der Ende, \& Verhulst, 2003; Leve, Kim, \& Pears, 2005). Nevertheless, surprisingly limited attention has been given to the temporal ordering of aggressive behavior and depressive symptoms during early adolescence, while knowledge about this is critical for the development of effective preventive interventions.

Several issues have arisen in the existing longitudinal studies examining the temporal ordering of aggressive behavior and depressive symptoms. These studies used samples with different age ranges (Curran \& Bollen, 2001; Van Lier \& Koot, 2010), employed different types of reporters (Burt, Obradović, Long, \& Masten, 2008; Measelle, Stice, \& Hogansen, 2006; Vieno, Kiesner, Pastore, \& Santinello, 2008), and used broadband constructs of externalizing and internalizing problems (Masten et al., 2005; Moilanen, Shaw, \& Maxwell, 2010). Due to these methodological differences, it is difficult to fully delineate the bidirectional association between aggressive and depressive symptomatology and, therefore, an important question remains how aggressive behavior and depressive symptoms are longitudinally associated in early adolescence. Therefore, the current study addresses the limitations of earlier studies by examining the bidirectional associations of aggressive behavior and depressive symptoms over the course of early adolescence, while using a multi-informant cross-lagged panel model.

\section{Longitudinal associations between aggressive behavior and depressive symptoms}

Several models have been proposed to explain the association between aggressive behavior and depressive symptoms over time. First, the failure model (Capaldi, 1992) holds that aggressive behavior precedes or predicts depressive symptoms. Specifically, aggressive behaviors may result in rejection and a lack of support by important others (i.e., parents), which in turn may lead to pervasive failure experiences in social interactions with these important others. Failure experiences may eventually lead to an increased risk for depressive moods. Second, the acting-out model states that depressive symptoms precede or predict aggressive behavior. According to this theory, underlying depressive feelings of children and preadolescents are acted out by displaying aggressive behavior (Carlson \& Cantwell, 1980).
Most longitudinal studies suggesting a failure model (Capaldi \& Stoolmiller, 1999; Kosterman et al., 2010), an acting-out model (Ritakallio et al., 2008), bidirectional associations (Beyers \& Loeber, 2003; Measelle et al., 2006), or no cross-lagged associations (Ingoldsby, Kohl, McMahon, \& Lengua, 2006; Overbeek et al., 2006) during adolescence did not use fully recursive cross-lagged path models (Neyer \& Asendorpf, 2001). This means, for instance, that studies proposing a failure model could not rule out the alternative explanation of the acting-out model, because they did not include predictive associations from depressive symptoms on aggressive behavior in the same analytical model. Only fully recursive cross-lagged path models can disentangle the direction of effects between aggressive behavior and depressive symptoms, by examining cross-lagged associations from aggressive behavior to depressive symptoms (failure model) and from depressive symptoms to aggressive behavior (acting-out model) in one longitudinal path model. These fully recursive models also control for concurrent associations and construct stability, to prevent that predictive associations between aggressive behavior and depressive symptom are spurious and either due to concurrent correlations at any of the waves or to the stability of the constructs across time. The existing longitudinal studies that applied these fully recursive models, often used more broadband measures of externalizing and internalizing problems and results were highly inconsistent.

First, there are several longitudinal studies during the childhood years, using fully recursive models, which provide evidence for a failure model. A recent study that used multi-informant data of teachers and peers showed that children with higher levels of externalizing problems at age 6 were also at risk for developing internalizing problems at age 10 , which was partially explained by poor peer relations (Van Lier \& Koot, 2010). Furthermore, using a combination of teacher, mother, and observer-reported instruments Moilanen et al. (2010) demonstrated with a childhood sample of at-risk boys that externalizing problems were directly associated with internalizing problems during the early school years (age 6-8) and the transition to adolescence (ages 11-12). A recent study with an older sample from ages 8 to 14 found that earlier levels of childhood antisocial behavior were related to later levels of adolescents' depressive symptoms as reported by mothers (Curran \& Bollen, 2001). In sum, these aforementioned studies provide longitudinal evidence that aggressive behavior predict depressive symptoms from childhood to early adolescence.

Second, longitudinal studies suggesting an acting-out model is less consistent by comparison. One Italian study found with a cross-lagged panel model that self-reported depression at age 12 predicted subsequent perceived antisocial behavior at age 13 (Vieno et al., 2008). There is more evidence based on adolescent reports suggesting that from age 15 to 17 only girls' depressed mood predicted subsequent delinquency (Wiesner, 2003). Although this last study provided evidence for an actingout model during adolescence, it also provided evidence for a failure model, indicating that depressive symptoms also predicted later levels of aggressive behavior. Therefore, these results 
underlined the bidirectional associations between depressed mood and aggressive behavior more than just the existence of an actingout model.

Finally, to make the literature even more complex, three other longitudinal studies during adolescence all failed to find crosslagged associations over time between self-reported delinquency and depressive symptoms (Akse, Hale, Engels, Raaijmakers, \& Meeus, 2007; Overbeek, Vollebergh, Meeus, Engels, \& Luijpers, 2001), and between self-reported conduct problems and depressive symptoms (Herrenkohl et al., 2010). All three studies used self-reports of adolescents which could lead to spurious relations due to response bias (Vierhaus \& Lohaus, 2008). Additionally, two of these studies (Akse et al., 2007; Overbeek et al., 2001) focused on delinquency while most other studies that found lagged associations used a broader category of externalizing problems (e.g., Curran \& Bollen, 2001). Nevertheless, two other studies (Burt et al., 2008; Masten et al., 2005) that used the same longitudinal cohort which was followed from age 10 till age 30 and which were assessed with multi-informant measures of internalizing and externalizing problems, also failed to find cross-lagged associations during adolescence. Although externalizing problems were concurrently and positively linked to internalizing problems, no significant longitudinal associations were found from early to late adolescence. Results only suggested that more internalizing problems predicted a relative decline in externalizing problems from late adolescence into emerging adulthood. These findings might suggest that during late adolescence and early adulthood problems in one domain can counteract growth in the other domain.

Additionally, whenever these aforementioned longitudinal studies examined gender differences, the same results were often applicable to both boys and girls. For example, results suggesting a failure model were found for both boys and girls in childhood (Van Lier \& Koot, 2010) and during adolescence (Curran \& Bollen, 2001). Also, a study that suggested an acting-out model did not find differences among early adolescent boys and girls (Vieno et al., 2008), and another studied failed to find cross-lagged associations between self-reported delinquency and depressive symptoms for both adolescent boys and girls (Overbeek et al., 2001). In contrast, bidirectional associations between self-reported delinquent behavior and depressive symptoms were only found for middle adolescent girls (Wiesner, 2003). In sum, most of these empirical studies indicate that the temporal ordering is the same for boys and girls. However, it remains unclear whether the same results will be found when examining gender differences in the bidirectional associations between aggressive behavior and depressive symptoms during early adolescence.

\section{Goals of the current study}

Altogether, results of the aforementioned longitudinal studies are highly mixed. Some studies suggested a failure model, but most of these studies did not employ fully recursive cross-lagged panel models (e.g., Kosterman et al., 2010), or they used childhood samples (e.g., Van Lier \& Koot, 2010). The single study that demonstrated an acting-out model from age 12 to 13 used self-reported data of adolescents (Vieno et al., 2008), which could lead to spurious associations due to response bias. Another study, which suggested bidirectional associations from age 13 to 18 between depressed mood and subsequent delinquency, found that the results were only applicable to adolescent girls (Wiesner, 2003). Some studies even did not find significant cross-lagged paths over the course of adolescence (e.g, Akse et al., 2007; Masten et al., 2005). Most importantly, these studies all used different measures of externalizing and internalizing problems, and none of these studies specifically examined the bidirectional link between aggressive behavior and depressive symptoms. So, existing studies examined younger or older samples, used self-reported data, administered measures of more broadband externalizing problems or delinquency, or did not employ fully recursive analytic models.

These limitations underscore the need for additional research on the longitudinal interconnections among aggressive behaviors and depressive symptoms in adolescence using fully recursive models. This is, to the best of our knowledge, the first study examining with a multi-informant cross-lagged panel model the longitudinal associations between aggressive behavior and depressive symptoms during early adolescence. We specifically focus on these associations during early adolescence, because this is an age period in which the occurrence of depressive symptoms and aggressive behavior change dramatically (Bongers et al., 2003). Knowledge about the temporal ordering of these problems during this age period is critical for prevention efforts. We also used multi-informant data to avoid possible confounds of method variance in this study (Vierhaus \& Lohaus, 2008); the measure of aggressive behavior was obtained from parental reports whereas the measure of depressive symptoms was based on adolescents self-report. Additionally, this study is among the first to examine gender differences in the temporal ordering of aggressive behavior and depressive symptoms during early adolescence with a multi-informant approach. In line with earlier studies examining bidirectional associations between more broadband externalizing and internalizing problems, we expect that we will not find gender differences in the longitudinal associations between aggressive behavior and depressive symptoms during early adolescence.

\section{Method}

\subsection{Sample}

Data were taken from the Research on Adolescent Development And Relationships (RADAR) project, which is an ongoing longitudinal study in the Netherlands that focuses on the development of relationships and behavior problems. For this study, we used the first three annual waves of questionnaire data. The longitudinal sample consists of 497 adolescents ( $56.9 \%$ boys) and their parents. The mean age at the first wave was 13 years $(S D=.05)$ and adolescents were in the first grade of junior high school. Most adolescents (85.2\%) lived in intact families. Adolescents classified as "at risk" (those having a score at or above the borderline clinical range of the TRF externalizing scale [T-score $\geq 60$ ]) were overrepresented $(n=206)$ in this sample.

In the current study sample attrition was low, namely $6.2 \%$ at T2, 4.6\% at T3, and $10.26 \%$ in from Wave 1 to 3. Little's (1988) Missing Completely At Random (MCAR) Test produced a normed $\chi^{2}$ $\left(\chi^{2} / \mathrm{d} f\right)$ of 1.10 . This indicates that it is likely the data were missing at random, and that it is safe to impute missing items (Bollen, 1989). So, respondents with missing values could be included in all model estimations in Mplus using Full Information Maximum Likelihood, resulting in the same sample size for each model (Muthén \& Muthén, 2007).

\subsection{Procedure}

To obtain this sample (for more details, see Van Lier et al., 2013), out of all regular primary education schools in the western and central parts of the Netherlands 429 schools were randomly selected and were subsequently approached to participate. We used a two-step inclusion phase (teacher screen followed by parent interviews) to select the 497 families of our study. First, teacher ratings of behavior problems were collected. Because of a specific focus of the RADAR study on delinquency development, we 
wanted to oversample adolescents at increased risk for developing externalizing symptoms. High risk was determined by teacher ratings of the externalizing scales of the Teacher's Report Form (Achenbach, 1991; Verhulst, Van der Ende, \& Koot, 1997); adolescents who received a T-score greater or equal to 60 were labeled as "at risk". This resulted in including 457 "at risk" adolescents, and 1087 "control" adolescents who were approached separately in the second selection phase of the study. Second, parents of 1544 adolescents were approached by phone; 463 adolescents were excluded because they did not meet requirements for inclusion in the study (both parents present, and presence of a sibling above or of 10 years), and 538 actively refused to participate. Non-participation in the RADAR study was not related to the target adolescents' gender $\left(\chi^{2}[1, N=1544]=2.75, p=.100, \varphi=0.04\right)$, not related to TRF externalizing behavior scores of "control" adolescents ( $F[1$, $\left.1085]=0.03, p=.880, \eta^{2}=0.00\right)$, and not related to TRF externalizing behavior scores of "at risk" adolescents $(F[1,455]=2.02$, $\left.p=.160, \eta^{2}=0.01\right)$. Eventually, 497 parents and adolescents provided informed consent of which 206 adolescents were classified as "at risk" and 291 adolescents were classified as"control".

Each year, adolescents, fathers and mothers filled in questionnaires during home visits. In addition to the written instructions trained research assistants provided verbal instructions about the questionnaires. Families received $€ 100$ per home-visit. This study was approved by the medical ethics committee of the University Medical Center in Utrecht.

\subsection{Measures}

\subsubsection{Depressive symptoms}

The Reynolds Adolescent Depression Scale 2nd edition (RADS2) was used to assess adolescents' depressive symptoms. This is a self-report measure designed as a clinical tool for the identification of depression in adolescents (Reynolds, 2002). Adolescent completed the subscales "Dysphoric Mood" (eight items; "I feel like crying"), "Negative Self-Evaluation" (eight items; "I feel I am bad") and "Somatic Complaints" (seven items; "I am tired"). Items were rated on a four-point scale ranging from 1 (almost never) to 4 (most of the time), and items were averaged to compute a mean score, with higher mean scores indicating higher levels of depressive symptoms. Internal consistency, test-retest reliability, and validity all have been strongly established (Myers \& Winters, 2002). The RADS-2 was translated to Dutch using the procedure described by Varni, Seid, and Rode (1999), including forward and backward translation, and pilot testing. In the current study, Cronbach's alphas of depressive symptoms ranged from .93 to .94 over the three measurement waves.

\subsubsection{Aggressive behavior}

Aggression was measured using the Aggressive Behavior scale score (20 items) on the Child Behavior CheckList (Achenbach \& Edelbrock, 1983). Fathers and mothers rated on a 3-point scale ( $0=$ not true, $1=$ somewhat true, $2=$ very true or often true) how frequently their adolescents engaged in aggressive behaviors, such as "gets in many fights" and "destroys others' belongings". Items were averaged to compute a mean score for fathers and mothers, with higher mean scores indicating that higher levels of adolescents' aggressive behavior were reported by fathers and mothers. Correlations between mean scores of mothers and fathers all were significant and ranged from .44 to .60 over the three measurement waves. Cronbach's alphas were .90 for mothers, .89 for fathers at all the three measurement waves. For each wave the scale scores of fathers and mothers were collapsed into one parent score by computing their mean. The CBCL was translated and validated for use in the Netherlands (Verhulst, Van der Ende, \& Koot, 1996).

\subsection{Strategy of analyses}

To examine the hypothesized bidirectional relations between adolescents' aggressive behavior and depressive symptoms over time, path analyses with cross-lagged effects were estimated using the software Mplus Version 5 (Muthén \& Muthén, 2007). The path model takes into account the stability of aggressive behavior and depressive symptoms over time, and the within-wave correlations between these variables. We used multi-group analyses to explore whether gender differences existed in the associations. In addition, we used Robust Maximum Likelihood Estimation to take into account the non-normal distribution of the aggressive behavior and depressive symptoms data (Enders \& Bandalos, 2001).

The first step in the analyses was to examine a fully constrained model that included stability paths and within-wave correlations of aggressive behavior and depressive symptoms (Model 1). Withinwave correlations refer to Wave 1 cross-sectional correlations and to correlated change in Wave 2 and Wave 3. In this fully constrained model we fixed the stability paths between the adjacent waves and the correlated change (Wave 2 and 3) across waves and between boys and girls. In subsequent models we have added hypothesized cross-lagged paths to this model, and we examined whether this improved the goodness-of-fit of the total model. More specifically, Model 2 examined the lagged paths between aggressive behavior and depressive symptoms, Model 3 examined the lagged associations between depressive symptoms and aggressive behavior, and Model 4 examined the cross-lagged (or bidirectional) associations between the study variables. In addition to the stability paths and within wave correlations the lagged paths from depressive symptoms to aggressive behavior and from aggressive behavior to depressive symptoms were also fixed across waves. With Model 5, it was tested with an unconstrained model whether it was possible to freely vary all paths in the model across waves.

The second step in the analyses was to examine whether the longitudinal associations differed between boys and girls. For the model that fitted the data best, we compared a fully constrained model with an unconstrained model to test whether it was allowed to vary lagged paths from aggressive behavior to depressive symptoms between boys and girls. Because adolescents at increased risk for developing externalizing symptoms were oversampled in the current study, we also tested for the final model whether there were differences between adolescents of the "at risk" group and the control group in the longitudinal associations.

To determine the goodness-of-fit of the models the following global fit measures were used: Chi-Square/degrees of freedom $\left(\chi^{2} / \mathrm{d} f\right)$ ratio, Comparative Fit Index (CFI), and the Root Mean Square Error of Approximation (RMSEA). According to Kline (2005), a good fitting model is one in which the $\chi^{2} / \mathrm{d} f$ ratio is less than 3 , the CFI is larger than .95, and the RSMEA is smaller than .08. The model was selected that fitted the data best and that was the most parsimonious model. Model comparisons were conducted using Robust $\chi^{2}$ difference tests (Satorra \& Bentler, 2001). Relatively higher CFI's and lower RMSEA's indicated a better model fit.

\section{Results}

\subsection{Descriptives}

Repeated measures ANOVA revealed a small but significant decrease in aggressive behavior from Wave 1 to Wave 3 ( $F[2$, $\left.443]=4.26, p=.015, \eta^{2}=.02\right)$. The interaction between gender and time was not significant $(F[2,443]=.19, p=.824)$, which means that the change in aggressive behavior did not differ significantly for boys and girls over the three waves. Results also showed that depressive symptoms changed significantly over the waves $(F[2$, 
Table 1

Correlation coefficients between early adolescents' aggressive behavior and depressive symptoms.

\begin{tabular}{llllll}
\hline \multicolumn{5}{l}{ Aggressive behavior } \\
\cline { 2 - 6 } & Wave 1 & Wave 2 & Wave 3 & M & SD \\
\hline Depressive symptoms & & & & & \\
Wave 1 & $.27^{* *}$ & $.25^{* *}$ & $.20^{* *}$ & 1.63 & .49 \\
Wave 2 & $.22^{* *}$ & $.27^{* *}$ & $.24^{* *}$ & 1.51 & .50 \\
Wave 3 & $.23^{* *}$ & $.23^{* *}$ & $.28^{* *}$ & 1.54 & .54 \\
M & .39 & .38 & .36 & & \\
SD & .27 & .28 & .27 & & \\
\hline
\end{tabular}

** $p<01$.

$\left.458]=11.71, p<.001, \eta^{2}=.05\right)$. Although effects were small, depressive symptoms decreased from Wave 1 to Wave 2, but increased from Waves 2 to 3 . And although the interaction between gender and time was small, girls showed significantly more depressive symptoms over time than boys $\left(F[2,458]=6.67, p=.001, \eta^{2}=.03\right)$.

Using the Fisher r-to-z transformation the significance of the difference between Pearson correlation coefficients was calculated. No significant gender differences were found in the Pearson correlations between aggressive behavior and depressive symptoms from Waves 1 to 3 . The means, standard deviations, and bivariate correlations for all study variables are presented for the total sample in Table 1.

\subsection{Model comparison}

Fig. 1 provides the final graphical model of the relations between aggressive behavior and depressive symptoms, and Table 2 shows the model fit indices and the model comparison tests of the different models. We started the analyses with a constrained model, in which all of the estimated parameters were required to be equal across waves and gender. The analyses revealed that the goodnessof-fit improved significantly when lagged paths from aggressive behavior to depressive symptoms were added to the model (see Model 2), but not when lagged paths from depressive symptoms to aggressive behavior were added to the model (see Model 3). When cross-lagged paths were added, this did not result in a significant improvement of the model fit compared to Model 2 (see Model 4).

Next, an unconstrained model was examined in which stability paths, concurrent associations, and lagged paths from aggressive behavior to depressive symptoms were allowed to vary across waves (see Model 5). The fit of this unconstrained model was compared to the best fitting constrained model (Model 2). It appeared that freely varying all model paths across waves did not significantly improve the model fit, which indicated that the model was equivalent across waves. The same results were obtained when freely varying stability paths, concurrent associations, lagged paths across waves in separate models. Thus, model comparisons showed that Model 2 was the most parsimonious and offered the best fit in comparison to the other models $(\chi \mathrm{SB} 2[10]=53.23$; $\mathrm{CFI}=.96$; RMSEA $=.093$ ).

Subsequently, for the best fitting model (Model 2) we tested with multi-group analyses whether the lagged paths between aggressive behavior and depressive symptoms could be constrained to be equal for boys and girls. Chi-square difference tests showed that varying lagged paths across gender did not significantly improve the model fit, $(\Delta \chi \operatorname{SB} 2(1, n=497)=.88, p=.347)$. As expected, this indicates that there were no gender differences in the longitudinal associations between aggressive behavior and depressive symptoms. Additionally, these associations did not differ for adolescents in the "at risk" group and the control group ( $\Delta \chi \mathrm{SB} 2(1$, $n=497)=.12, p=.731)$.

\subsection{Model results}

Altogether, the results revealed (Fig. 1) lagged paths from aggressive behavior to depressive symptoms. Hence, more aggressive behavior of adolescents significantly predicted more subsequent depressive symptoms. These lagged paths were significant even after controlling for initial levels of all variables and for their cross-time stability. However, no significant lagged paths from depressive symptoms to aggressive behavior were found. The pattern of findings appeared to be the same over time for adolescent boys and girls and for adolescents in the "at risk" group and the control group. The results also showed significant withinwave correlations between adolescents' aggressive behavior and their depressive symptoms. Higher levels of aggressive behavior were related to more depressive symptoms of adolescents (i.e., T1 correlation), and a relative increase in aggressive behavior was associated with a relative increase in depressive symptoms of adolescents (i.e., correlated change at T2 and T3). The model also showed considerable stability of behavior problems, especially of aggressive behavior.

\section{Discussion}

The current longitudinal study examined the bidirectional associations of aggressive behavior and depressive symptoms during early adolescence and whether gender moderated these associations. The longitudinal design allowed us to examine the expectations of two contrasting perspectives about the temporal ordering of depressive symptoms and aggressive behavior: The failure model (Capaldi, 1992), which suggests that aggressive behavior precede or predict depressive symptoms, and the acting-out model (Carlson \& Cantwell, 1980), which states that depressive symptoms precede or predict aggressive behaviors.

Our multi-informant cross-lagged panel analyses revealed that as expected aggressive behavior and depressive symptoms were concurrently and longitudinally linked during early adolescence. Consistent with the failure model, it appeared that early adolescents' aggressive behavior predicted subsequent higher levels of depressive symptoms. However, this study does not provide support for an acting-out model, because we did not find significant longitudinal associations from depressive symptoms to aggressive behavior. The observed associations were operating similarly across female and male adolescents in this sample.

\subsection{Longitudinal associations between aggressive behavior and depressive symptoms}

Our results, thus, provide support for the failure model (Capaldi, 1992) because during early adolescence higher levels of aggressive behavior predicted subsequent higher levels of depressive symptoms. Our results are in line with earlier longitudinal studies that suggested a failure model in childhood (Van Lier \& Koot, 2010), adolescence (Curran \& Bollen, 2001), and with broadband constructs of externalizing problems (Moilanen et al., 2010). This study also showed positive concurrent associations, indicating that adolescents who show more aggressive behavior also perceived more depressive symptoms (Wolff \& Ollendick, 2006). Furthermore, construct stability (i.e., autocorrelations for aggressive behavior and depressive symptoms) was moderate to strong, which underscores the importance of early identification and prevention efforts prior to adolescence. Often (cross-)lagged effects are statistically difficult to find when concurrent associations are moderate and when construct stability is high (Neyer \& Asendorpf, 2001). However, even when controlling for these associations in our fully recursive cross-lagged model, we found small but significant lagged 
CO-OCCURRENCE IN EARLY ADOLESCENCE

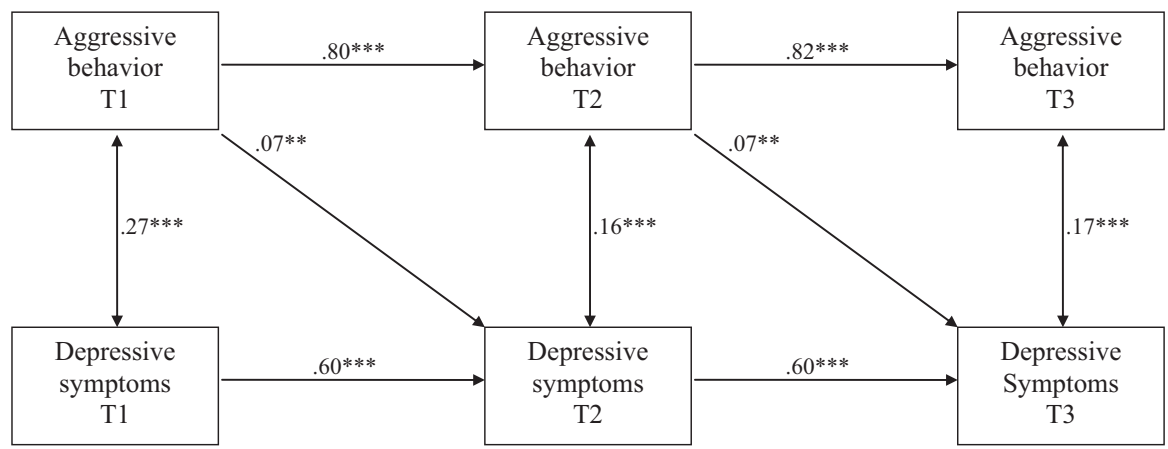

Fig. 1. Longitudinal associations between early adolescents' aggressive behavior and depressive symptoms for the total sample.

effects. Therefore, confidence can be placed in the present findings that aggressive behavior predicts subsequent depressive symptoms during early adolescence.

The current literature suggests several possible explanations why aggressive behavior predicts subsequent depressive symptoms during adolescence. The link has been explained by developmental cascades between competence and behavior problems (Capaldi, 1992; Masten \& Cicchetti, 2010). It is thought that aggressive behavior leads to multiple failures experienced by adolescents, such as academic skill deficits and rejection by the family and by peers, which in turn may lead to depressed mood. Several studies found evidence for developmental cascades from externalizing problems to diminished social competence to internalizing problems from early childhood to late childhood (Van Lier \& Koot, 2010) and from childhood to young adulthood (Masten et al., 2005). Additionally, cascade paths were also found from externalizing problems at age 6 to low academic competence at age 8 to internalizing problems at age 10 (Moilanen et al., 2010). Although these studies underline that social and academic failures can potentially explain the association from aggressive behavior to depressive symptoms, our small lagged effects do not suggest such developmental cascading effects. It is much more likely that the link between aggressive behavior and depressive symptoms can be explained by common risk factors (Keiley et al., 2003). For example, a common genetic liability has been found to explain $45 \%$ of the observed covariation between antisocial behavior and depressed mood (O'Connor, McGuire, Reiss, Hetherington, \& Plomin, 1998). Also, parents of adolescents with both depressive symptoms and conduct problems showed the lowest levels of warmth and the highest level of hostility during interactions (Ge, Best, Conger, \& Simons, 1996). Finally, research also suggested that aggressive and depressive children both demonstrate social cognitive distortions (Quiggle, Garber, Panak, \& Dodge, 1992; Rudolph \& Clark, 2001). Although we were not able to examine these risk factors, results of the current study may be explained by the presence of risk factors common to both aggressive and depressive symptomatology during adolescence. Therefore, we believe that more research is needed that specifically addresses the role of these common risk factors in the longitudinal association between aggressive behavior and depressive symptoms during adolescence.

Furthermore, the pattern of longitudinal associations found in this study was the same for adolescent boys and girls. This is line with several studies who did not find gender differences in the temporal ordering of more broadband externalizing and internalizing problems (e.g., Van Lier \& Koot, 2010; Vieno et al., 2008). As expected, the present study thus suggests that during early adolescence aggressive behavior predicts depressive symptoms in similar ways for boys and girls. For prevention and intervention it is thus important that both boys and girls are targeted. The next step is to explore gender differences with regard to explanatory mechanisms.

Our results did not support the acting-out model that proposes that depressive symptoms precede aggressive behavior (Carlson \& Cantwell, 1980). This could be due to several reasons. For example, Patterson, Reid, and Dishion (1992) proposed a transactional association over time between depressive and aggressive symptomatology. Aggressive behaviors during childhood and early adolescence are likely to produce academic skill deficits, rejection by the family and peers, and low self-esteem, which is associated with depressive symptoms over time. In turn, rejection by the family and peers is an important prelude to deviant peer group membership, which is related to more aggressive behaviors, because deviant peers are thought to support aggressive behaviors. Studies, indeed, have reported transactional associations between depressive symptoms and externalizing problems. More specifically, there is evidence for a robust effect from depressed mood on delinquency trajectories from middle to late adolescence (Beyers \& Loeber, 2003). Additionally, conduct problems at age 27 are found to predict depression at age 30 (Herrenkohl et al., 2010). Thus, it could be possible that this study was not able to capture lagged

Table 2

Longitudinal model fit indices and model comparison tests.

\begin{tabular}{|c|c|c|c|c|c|c|c|c|c|}
\hline & \multicolumn{5}{|c|}{ Model fit indices } & \multicolumn{4}{|c|}{ Model comparison tests } \\
\hline & $(\mathrm{d} f)$ & $\operatorname{MLr} \chi^{2}$ & $\chi^{2}(\mathrm{~d} f)$ & CFI & $\overline{\text { RMSEA }}$ & & $\Delta \chi \mathrm{SB}^{2}$ & $\Delta \mathrm{d} f$ & $p$ \\
\hline Constrained baseline model & 11 & 58.76 & 5.34 & .95 & .093 & & & & \\
\hline Lagged paths aggressive behavior to depressive symptoms & 10 & 53.23 & 5.32 & .96 & .093 & 2 vs. 1 & 5.53 & 1 & .019 \\
\hline Lagged paths depressive symptoms to aggressive behavior & 10 & 56.10 & 5.61 & .95 & .096 & 3 vs. 1 & 2.66 & 1 & .164 \\
\hline $\begin{array}{l}\text { Bidirectional paths depressive symptoms and aggressive } \\
\text { behavior }\end{array}$ & 9 & 50.72 & 5.64 & .96 & .097 & $\begin{array}{l}4 \text { vs. } 1 \\
4 \text { vs. } 2 \\
4 \text { vs. } 3\end{array}$ & $\begin{array}{l}8.04 \\
2.51 \\
5.38\end{array}$ & $\begin{array}{l}2 \\
1 \\
1\end{array}$ & $\begin{array}{l}.023 \\
.196 \\
.021\end{array}$ \\
\hline Unconstrained model: vary all model paths across waves & 6 & 44.52 & 7.42 & .96 & .114 & 5 vs. 2 & 8.71 & 4 & .068 \\
\hline
\end{tabular}


effects from depressive symptoms to subsequent aggressive behavior due to our focus on early adolescence or our focus on aggressive behavior only.

Finally, the few longitudinal studies that found evidence for lagged paths from depressive symptoms to aggressive behavior during adolescence (Vieno et al., 2008; Wiesner, 2003) all used adolescent reports of depressive and aggressive symptoms. This could potentially have biased their results, because of shared method variance (Vierhaus \& Lohaus, 2008). The current study used a multiinformant approach and therefore more confidence can be placed in the robustness of the results.

\subsection{Strengths, limitations and future directions}

In sum, our results offer a significant contribution to the co-occurrence literature, because there is a clear paucity of longitudinal studies that examine both the temporal ordering of aggressive behavior and depressive symptoms and gender differences in this association over the course of early adolescence. A key strength of the present study is that we used a multi-informant cross-lagged panel model to disentangle longitudinal associations between aggressive behavior and depressive symptoms, and our large dataset permitted us to do meaningful analyses of gender differences. Depressive symptoms have been found to be best judged by self-report, because internalizing behaviors may only in part be observable to parents (Vierhaus \& Lohaus, 2008). Symptoms of aggressive behavior are for parents much easier to observe and more disruptive to family functioning, and therefore externalizing problems are more likely to attract attention from the parents than internalizing problems. The CBCL has, therefore, often been used to assess aggressive behavior (Achenbach, McConaughy, \& Howell, 1987). And although, our multi-informant approach reduces biases due to shared method variance, it can still be considered a limitation that we did not use multiple informants for each construct. It would be interesting to examine whether including data from multiple reporters for both aggressive behavior and depressive symptoms would yield the same conclusions.

Several limitations of this study should also be noted and addressed in future research. Firstly, the current results are limited to early adolescence. Although our results are in line with several earlier studies that suggested a failure model in childhood (Van Lier \& Koot, 2010) and adolescence (Curran \& Bollen, 2001), our small effects of aggressive behavior to depressive symptoms could be due to the age of our sample. Despite the increase in depressive symptoms during adolescence (Bongers et al., 2003), aggressive behavior usually peaks during childhood (Leve et al., 2005), and it is possible that our study started too late to capture stronger associations between aggressive behavior and depressive symptoms. As mentioned before, our focus on early adolescence and aggressive behavior could also explain why we did not find support for an acting-out model. It is possible that depressive symptoms are able to predict subsequent aggressive behavior during early childhood (Carlson \& Cantwell, 1980), from middle adolescence onwards (Beyers \& Loeber, 2003), or when using more broadband constructs of externalizing problems (Herrenkohl et al., 2010). Altogether, more research is needed that examines the temporal ordering between aggressive behavior and depressive symptoms from early childhood to late adolescence with cross-lagged panel models. Once patterns and timing of co-occurrence between aggressive behavior and depressive symptoms are clearly identified and replicated during these other age periods, the processes by which they occur can be more specifically examined.

Secondly, because some symptoms of depression overlap with symptoms of aggression, namely irritability and agitation, cooccurrence could be an artifact of overlapping symptomatology of aggression and depression questionnaires (Wolff \& Ollendick,
2006). However, empirical evidence demonstrated that eliminating these overlapping symptoms from both aggression and depression questionnaires did not result in lower levels of cooccurrence between aggression and depression, showing that the co-occurrence was not due to overlapping symptoms (Biederman, Faraone, Mick, \& Lelon, 1995). It is therefore unlikely that the longitudinal link between depressive symptoms and aggressive behavior can be explained by symptom overlap of the Aggressive Behavior Scale of the CBCL and the Reynolds Adolescent Depression Scale.

Thirdly, although adolescents at increased risk for developing externalizing symptoms were oversampled in the current study, we did not find differences in temporal ordering of aggressive behavior and depressive symptoms between the "at risk" group and the control group. Extending the current study to clinical populations could increase our understanding of the cooccurrence between aggression and depression (Burke, Loeber, Lahey, \& Rathouz, 2005; Harrington, Fudge, Rutter, Pickles, \& Hill, 1991; Lahey, Loeber, Burke, Rathouz, \& McBurnett, 2002). Even though some co-occurrence studies based on community samples used clinical cut-off points to define a particular criterion level above which respondents showed a significant risk for a psychiatric diagnostic disorder (Ge et al., 1996; Overbeek et al., 2006), the present study did not use such cut-off points. This study used the full range of information about behavior problems available in the data. We also investigated subclinical levels of aggressive behavior, because even low levels of aggressive behaviors, such as lying and fighting, are perceived as socially undesirable (Tremblay, 2000). Our results indeed underline the importance of also investigating subclinical levels, because low levels of aggressive behavior were still predictive of subsequent depressive symptoms.

Finally, the current data were gathered from a relatively ethnic homogeneous sample of adolescents, which limits the external validity of the findings. Future research could contribute to the present literature by employing other samples in terms of cultural background.

\section{Conclusion and implications}

The present study showed that early adolescents' aggressive behavior predicted their subsequent depressive symptoms. Consistent with a failure model, male and female adolescents' interpersonal problems seem associated with later depressive symptoms. The fully recursive and longitudinal nature of this study provides assurance that the temporal effect and model results are tenable.

This study underlines the importance of considering crossdomain effects for prevention and intervention. Reducing aggressive behavior before or at the start of adolescence might reduce the risk for subsequent depressive symptoms. And although early adolescent boys may show higher levels of aggressive behavior than girls, our results underline the importance that aggressive girls should also be targeted for prevention and intervention. Moreover, because of the high stability of both aggressive behaviors and depressive symptoms, prevention and intervention should take place as soon as possible.

\section{Disclosure of interest}

The authors declare that they have no conflicts of interest concerning this article.

\section{References}

Achenbach, T. M.(1991). Manual for the youth self-report and 1991 profile. Burlington, VT: University of Vermont, Department of Psychiatry. 
Achenbach, T. M., \& Edelbrock, C. (1983). Manual for the child behavior checklist and revised child behavior profile. Burlington, VT: University of Vermont, Department of Psychiatry.

Achenbach, T. M., McConaughy, S. H., \& Howell, C. T. (1987). Child/adolescent behavioral and emotional problems: Implications of cross-informant correlations for situational specificity. Psychological Bulletin, 101, 213-232. http://dx.doi.org/10.1037//0033-2909.101.2.213

Akse, J., Hale, B., Engels, R., Raaijmakers, Q., \& Meeus, W. (2007). Co-occurrence of depression and delinquency in personality types. European Journal of Personality, 21, 235-256. http://dx.doi.org/10.1002/per.604

Angold, A., Costello, E. J., \& Erkanli, A. (1999). Comorbidity.Journal of Child Psychology and Psychiatry, 40, 57-87. http://dx.doi.org/10.1111/1469-7610.00424

Beyers, J. M., \& Loeber, R. (2003). Untangling developmental relations between depressed mood and delinquency in male adolescents. Journal of Abnormal Child Psychology, 31, 247-266, doi:0091-0627/03/0600-0247/0.

Biederman, J., Faraone, S., Mick, E., \& Lelon, E. (1995). Psychiatric comorbidity among referred juveniles with major depression: Fact or artifact? Journal of the American Academy of Child E Adolescent Psychiatry, 34, 579-590, doi:0.1097/00004583199505000-00010.

Bollen, K. A. (1989). Structural equation models. New York: Wiley Online Library.

Bongers, I. L., Koot, H. M., Van der Ende, J., \& Verhulst, F. C. (2003). The normative development of child and adolescent problem behavior. Journal of Abnormal Psychology, 112, 179-192. http://dx.doi.org/10.1037/0021-843X.112.2.179

Burke, J. D., Loeber, R., Lahey, B. B., \& Rathouz, P. J. (2005). Developmental transitions among affective and behavioral disorders in adolescent boys. Journal of Child Psychology and Psychiatry, 46, 1200-1210. http://dx.doi.org/10.1111/j.1469-7610.2005.00422.x

Burt, K. B., Obradović, J., Long, J. D., \& Masten, A. S. (2008). The interplay of social competence and psychopathology over 20 years: Testing transactional and cascade models. Child Development, 79, 359-374. http://dx.doi.org/10.1111/j.1467-8624.2007.01130.x

Capaldi, D. M. (1992). Co-occurrence of conduct problems and depressive symptoms in early adolescent boys: II. A 2-year follow-up at grade 8. Development and Psychopathology, 4, 125-144. http://dx.doi.org/10.1017/S0954579400005605

Capaldi, D. M., \& Stoolmiller, M. (1999). Co-occurrence of conduct problems and depressive symptoms in early adolescent boys: III. Prediction to young-adult adjustment. Development and Psychopathology, 11, 59-84. http://dx.doi.org/10.1017/S0954579400005605

Carlson, G. A., \& Cantwell, D. P. (1980). Unmasking masked depression in children and adolescents. American Journal of Psychiatry, 137, 445-449. Retrieved from http://ajp.psychiatryonline.org/cgi/content/abstract/137/4/445

Colman, I., Murray, J., Abbott, R. A., Maughan, B., Kuh, D., Croudace, T. J., \& Jones, P. B. (2009). Outcomes of conduct problems in adolescence: 40 year follow-up of national cohort. British Medical Journal, 338, 208-226. http://dx.doi.org/10.1136/bmj.a2981

Curran, P. J., \& Bollen, K. A. (2001). The best of both worlds: Combining autoregressive and latent curve models. In L. M. Collins, \& A. G. Sayer (Eds.), New methods for the analysis of change (pp. 107-135). Washington, DC: American Psychological Association.

Enders, C. K., \& Bandalos, D. L. (2001). The relative performance of full information maximum likelihood estimation for missing data in structural equation models. Structural Equation Modeling: A Multidisciplinary Journal, 8, 430-457. http://dx.doi.org/10.1207/S15328007SEM0803_5

Fergusson, D. M., \& Woodward, L. J. (2002). Mental health, educational, and social role outcomes of adolescents with depression. Archives of General Psychiatry, 59, 225-231. http://dx.doi.org/10.1001/archpsyc.59.3.225

Ge, X., Best, K. M., Conger, R. D., \& Simons, R. L. (1996). Parenting behaviors and the occurrence and co-occurrence of adolescent depressive symptoms and conduct problems. Developmental Psychology, 32, 717-731. http://dx.doi.org/10.1037//0012-1649.32.4.717

Harrington, R., Fudge, H., Rutter, M., Pickles, A., \& Hill, J. (1991). Adult outcomes of childhood and adolescent depression: II. Links with antisocial disorders. Journal of the American Academy of Child \& Adolescent Psychiatry, 30, 434-439. http://dx.doi.org/10.1097/00004583-199105000-00013

Herrenkohl, T. I., Kosterman, R., Mason, W. A., Hawkins, J. D., McCarty, C. A., \& McCauley, E. (2010). Effects of childhood conduct problems and family adversity on health, health behaviors, and service use in early adulthood: Tests of developmental pathways involving adolescent risk taking and depression. Development and Psychopathology, 22, 655-665. http://dx.doi.org/10.1017/S0954579410000349

Ingoldsby, E. M., Kohl, G. O., McMahon, R. J., \& Lengua, L. (2006). Conduct problems, depressive symptomatology and their co-occurring presentation in childhood as predictors of adjustment in early adolescence. Journal of Abnormal Child Psychology, 34, 602-620. http://dx doi.org/10.1007/s10802-006-9044-9

Jackson, J., Kuppens, P., Sheeber, L. B., \& Allen, N. B. (2011). Expression of anger in depressed adolescents: The role of the family environment. Journal of Abnormal Child Psychology, 39, 463-474. http://dx.doi.org/10.1007/s10802-0109473-3

Kashani, J. H., Dahlmeier, J. M., Borduin, C. M., Soltys, S., \& Reid, J. C. (1995). Characteristics of anger expression in depressed children. Journal of the American Academy of Child and Adolescent Psychiatry, 34, 322-326. http://dx.doi.org/10.1097/00004583-199503000-00017

Keiley, M. K., Lofthouse, N., Bates, J. E., Dodge, K. A., \& Pettit, G. S. (2003). Differential risks of covarying and pure components in mother and teacher reports of externalizing and internalizing behavior across ages 5 to 14. Journal of Abnormal Child Psychology, 31, 267-283. http://dx.doi.org/10.1023/A:1023277413027
Kline, R. B. (2005). Principles and practice of structural equation modeling. New York: The Guilford Press.

Kosterman, R., Hawkins, J. D., Mason, W. A., Herrenkohl, T. I., Lengua, L. J., \& McCauley E. (2010). Assessment of behavior problems in childhood and adolescence as predictors of early adult depression. Journal of Psychopathology and Behaviora Assessment, 32, 118-127. http://dx.doi.org/10.1007/s10862-009-9138-0

Lahey, B. B., Loeber, R., Burke, J., Rathouz, P. J., \& McBurnett, K. (2002). Waxing and waning in concert: Dynamic comorbidity of conduct disorder with other disruptive and emotional problems over 7 years among clinic-referred boys. Journal of Abnormal Psychology, 111, 556-567. http://dx.doi.org/10.1037//0021-843X.111.4.556

Leve, L. D., Kim, H. K., \& Pears, K. C. (2005). Childhood temperament and family environment as predictors of internalizing and externalizing trajectories from ages 5 to 17. Journal of Abnormal Child Psychology, 33, 505-520. http://dx.doi.org/10.1007/s10802-005-6734-7

Little, R. J. A. (1988). A test of missing completely at random for multivariate data with missing values. Journal of the American Statistical Association, 83, 1198-1202. http://dx.doi.org/10.2307/2290157

Masten, A. S., \& Cicchetti, D. (2010). Developmental cascades. Development and Psychopathology, 22, 491-495. http://dx.doi.org/10.1017/S0954579410000222

Masten, A. S., Roisman, G. I., Long, J. D., Burt, K. B., Obradovic, J., Riley, J. R., \& Tellegen, A. (2005). Developmental cascades: Linking academic achievement and externalizing and internalizing symptoms over 20 years. Developmental Psychology, 41, 733-745. http://dx.doi.org/10.1037/0012-1649.41.5.733

Measelle, J. R., Stice, E., \& Hogansen, J. M. (2006). Developmental trajectories of co-occurring depressive, eating, antisocial, and substance abuse problems in female adolescents. Journal of Abnormal Psychology, 115, 524-538. http://dx.doi.org/10.1037/0021-843X.115.3.524

Moilanen, K. L., Shaw, D. S., \& Maxwell, K. L. (2010). Developmental cascades: Externalizing, internalizing, and academic competence from middle childhood to early adolescence. Development and Psychopathology, 22, 635-653. http://dx.doi.org/10.1017/S0954579410000337

Muthén, L. K., \& Muthén, B. O. (2007). Mplus: Statistical analysis with latent variables: User's guide. Los Angeles, CA: Muthén \& Muthén.

Myers, K., \& Winters, N. C. (2002). Ten-year review of rating scales. II: Scales for internalizing disorders. Journal of the American Academy of Child \& Adolescent Psychiatry, 41, 634-659. http://dx.doi.org/10.1097/00004583-200206000-00004

Neyer, F. J., \& Asendorpf, J. B. (2001). Personality-relationship transaction in young adulthood. Journal of Personality and Social Psychology, 81, 1190-1204. http://dx.doi.org/10.1037/0022-3514.81.6.1190

O'Connor, T. G., McGuire, S., Reiss, D., Hetherington, E. M., \& Plomin, R. (1998) Co-occurrence of depressive symptoms and antisocial behavior in adolescence: A common genetic liability. Journal of Abnormal Psychology, 107, 27-37. http://dx.doi.org/10.1037/0021-843X.107.1.27

Overbeek, G., Biesecker, G., Kerr, M., Stattin, H., Meeus, W., \& Engels, R. C. M. E. (2006). Co-occurrence of depressive moods and delinquency in early adolescence: The role of failure expectations, manipulativeness, and social contexts. International Journal of Behavioral Development, 30, 433-443. http://dx.doi.org/10.1177/0165025406071491

Overbeek, G., Vollebergh, W., Meeus, W., Engels, R., \& Luijpers, E. (2001). Course, co-occurrence, and longitudinal associations of emotional disturbance and delinquency from adolescence to young adulthood: A sixyear three-wave study. Journal of Youth and Adolescence, 30, 401-426. http://dx.doi.org/10.1023/A:1010441131941

Patterson, G. R., Reid, J., \& Dishion, T. (1992). A social interactional approach: Antisocia boys, Vol. 4. Eugene, OR: Castalia Publishing.

Quiggle, N. L., Garber, J., Panak, W. F., \& Dodge, K. A. (1992). Social information processing in aggressive and depressed children. Child Development, 63, 1305-1320. http://dx.doi.org/10.2307/1131557

Reynolds, W. M. (2002). Reynolds adolescent depression scale (2nd edition RADS-2. Professional Manual, pp. ). Lutz, FL: Psychological Assessment Recourses.

Ritakallio, M., Koivisto, A. M., von der Pahlen, B., Pelkonen, M., Marttunen, M. \& Kaltiala-Heino, R. (2008). Continuity, comorbidity and longitudinal associations between depression and antisocial behaviour in middle adolescence: A 2-year prospective follow-up study. Journal of Adolescence, 31, 355-370. http://dx.doi.org/10.1016/j.adolescence.2007.06.006

Rudolph, K. D. \& Clark, A. G. (2001). Conceptions of relationships in children with depressive and aggressive symptoms: Social-cognitive distortion or reality? Journal of Abnormal Child Psychology, 29, 41-56. http://dx.doi.org/10.1023/A:1005299429060

Satorra, A., \& Bentler, P. M. (2001). A scaled difference chi-square test statistic for moment structure analysis. Psychometrika, 66, 507-514. http://dx.doi.org/10.1007/BF02296192

Tremblay, R. E. (2000). The development of aggressive behaviour during childhood: What have we learned in the past century? International Journal of Behavioral Development, 24, 129-141. http://dx.doi.org/10.1080/016502500383232

Van Lier, P. A. C., Frijns, T., Neumann, A., den Exter Blokland, E., Koot, H. M., \& Meeus, W. The RADAR study: Design, description of sample, and validation of cohort assignment. (Manuscript submitted for publication).

Van Lier, P. A. C., \& Koot, H. M. (2010). Developmental cascades of peer relations and symptoms of externalizing and internalizing problems from kindergarten to fourth-grade elementary school. Development and Psychopathology, 22, 569-582. http://dx.doi.org/10.1017/S0954579410000283

Varni, J. W., Seid, M., \& Rode, C. A. (1999). The PedsQL: Measurement mode for the Pediatric Quality of Life Inventory. Medical Care, 37, 126-139. http://dx.doi.org/10.1097/00005650-199902000-00003 
Verhulst, F. C., Van der Ende, J., \& Koot, H. M. (1997). Handleiding voor de youth self-report (manual for the youth self-report, dutch version). Rotterdam, the Netherlands: Erasmus University Rotterdam.

Verhulst, F. C., Van der Ende, J., \& Koot, H. M. (1996). Handleiding voor de CBCL/4-18 (manual for the child behavior Checklist/4-18, dutch version). Rotterdam, the Netherlands: Erasmus University Rotterdam.

Vieno, A., Kiesner, J., Pastore, M., \& Santinello, M. (2008). Antisocial behavior and depressive symptoms: Longitudinal and concurrent relations. Adolescence, 43, 649-660 (Retrieved from http://www.psy.unipd.it/ mpastore/ papers/Vieno_etAl_2008.pdf)
Vierhaus, M., \& Lohaus, A. (2008). Children and parents as informants of emotional and behavioural problems predicting female and male adolescent risk behaviour: A longitudinal cross-informant study. Journal of Youth and Adolescence, 37, 211-224. http://dx.doi.org/10.1007/s10964-007-9193-3

Wiesner, M. (2003). A longitudinal latent variable analysis of reciprocal relations between depressive symptoms and delinquency during adolescence. Journal of Abnormal Psychology, 112, 633-645. http://dx.doi.org/10.1037/0021843X.112.4.633

Wolff, J. C., \& Ollendick, T. H. (2006). The comorbidity of conduct problems and depression in childhood and adolescence. Clinical Child and Family Psychology Review, 9, 201-220. http://dx.doi.org/10.1007/s10567-006-0011-3 